\title{
Imaging Techniques: Options for the Diagnosis and Monitoring of Treatment of Enthesitis in Psoriatic Arthritis
}

\author{
Catherine Bakewell ${ }^{\mathbb{D}}$, Sibel Zehra Aydin (iD), Veena K. Ranganath, Lihi Eder(D), \\ and Gurjit S. Kaeley (D)
}

\begin{abstract}
Psoriatic arthritis (PsA) affects up to $30 \%$ of patients with psoriasis and may include musculoskeletal manifestations such as enthesitis. Enthesitis is associated with joint damage, and early detection and treatment are essential to management of the disease. Traditionally assessed by clinical examination and conventional radiography, entheseal inflammation can now be more accurately assessed earlier in the disease using techniques such as ultrasound, magnetic resonance imaging, computed tomography, and molecular imaging. However, there is little consensus on the optimum definition for diagnosing enthesitis in PsA or on the ideal scoring system for measuring response to treatment. This review aims to summarize the benefits and limitations of different imaging modalities in the assessment of enthesitis. It also proposes that adoption of standardized definitions and validation of scoring systems and imaging techniques in clinical trials will allow the efficacy of new treatment options to be assessed more accurately. (First Release May 15 2020; J Rheumatol 2020;47:973-82; doi:10.3899/jrheum.190512)
\end{abstract}

Key Indexing Terms:

PSORIATIC ARTHRITIS MAGNETIC RESONANCE IMAGING ULTRASONOGRAPHY OUTCOME ASSESSMENT DIAGNOSTIC IMAGING

Psoriatic arthritis (PsA) is a chronic inflammatory disease that affects up to $30 \%$ of patients with psoriasis $^{1,2}$. Musculoskeletal manifestations of PsA may include

From the Intermountain Healthcare Medical Group, Salt Lake City, Utah, USA; University of Ottawa, Ottawa, Ontario, Canada; University of California, Los Angeles (UCLA), California, USA; Women's College Hospital, University of Toronto, Toronto, Ontario, Canada; University of Florida College of Medicine, Jacksonville, Florida, USA.

This review article was sponsored by Novartis Pharmaceuticals Corp., which manufactures secukinumab.

C. Bakewell has received consultancy fees from and/or served on speakers bureaus for AbbVie and Novartis Pharmaceuticals Corp. S.Z. Aydin has received honoraria from Novartis. V.K. Ranganath has served on the Data and Safety Monitoring Board for Amgen and has received grants for investigator-initiated studies from Mallinckrodt. L. Eder has received research or educational grants and/or consultancy fees from Novartis. G.S. Kaeley has received consultancy fees from Novartis.

C. Bakewell, MD, Rheumatologist, Intermountain Healthcare Medical Group Salt Lake Clinic; S.Z. Aydin, MD, Associate Professor in Rheumatology, University of Ottawa, Ottawa Hospital Research Institute; V.K. Ranganath, MD, MS, Health Sciences Associate Clinical Professor, Division of Rheumatology, David Geffen School of Medicine at UCLA; L. Eder, MD, PhD, Assistant Professor of Medicine, Women's College Research Institute, Women's College Hospital, University of Toronto; G.S. Kaeley, MBBS, MRCP, RhMSUS, Professor, Department of Medicine, Division of Rheumatology and Clinical Immunology, University of Florida College of Medicine.

Address correspondence to Dr. C. Bakewell, MD, RhMSUS, Intermountain Healthcare Medical Group, Salt Lake Clinic, 389 South 900 East, Salt Lake City, Utah 84102,USA.E-mail: bakewell@uw.edu

Full Release Article. For details see Reprints and Permissions at jrheum.org Accepted for publication October 23, 2019. peripheral arthritis, spondylitis in the spine, and enthesitis and/or dactylitis. PsA can affect multiple types of soft tissue and has a variable presentation of synovitis, which is commonly asymmetrical ${ }^{3}$.

About $60-80 \%$ of patients with PsA will develop enthesitis ${ }^{1}$, defined as inflammation of the entheses, the areas where tendons, ligaments, or joint capsules insert into the bone ${ }^{2}$. Enthesitis is one of the first signs of disease and has been proposed to be the primary lesion in $\mathrm{PsA}^{4}$, a finding that has led to its inclusion in the Classification Criteria for Psoriatic Arthritis (CASPAR) ${ }^{5}$ and the Group for Research and Assessment of Psoriasis and Psoriatic Arthritis (GRAPPA) core disease domains for $\mathrm{PsA}^{6}$. Enthesitis is also associated with joint damage and is an indicator of disease severity ${ }^{1}$. The importance of enthesitis is further highlighted by its inclusion in the Outcome Measures in Rheumatology (OMERACT) PsA core domain set, warranting evaluation in clinical trials and observational studies of PsA ${ }^{7}$.

Early diagnosis and treatment of PsA are critical given that delays in rheumatologic assessment by $\geq 6$ months are associated with longterm radiographic progression and detrimental functional outcomes ${ }^{8}$. Therefore, identifying enthesitis, a marker of early disease, can lead to early treatment initiation before irreversible structural damage occurs ${ }^{2}$. However, identifying enthesitis in the clinic can be challenging, and incorporating imaging modalities in the assessment of enthesitis may be useful.

Personal non-commercial use only. The Journal of Rheumatology Copyright @ 2020 . All rights reserved. 
This narrative review describes imaging modalities used to detect enthesitis and discusses ways in which standardized definitions and validated scoring systems and imaging techniques will allow a more accurate assessment of treatment options. We include relevant information identified from a targeted literature search (Supplementary Data 1, available with the online version of this article) focused on PsA, enthesitis, and the imaging techniques used in the assessment of enthesitis.

\section{Clinical assessment and imaging techniques used to assess enthesitis}

Clinical assessment. Palpation is used to detect the presence of local tenderness and soft tissue swelling in the clinical examination of enthesitis ${ }^{9}$ (Figure 1A). Physicians apply pressure to each site with the dominant thumb, until the nail bed blanches, asking patients to provide subjective reports of tenderness ${ }^{10}$. Several indices have been developed to help standardize the clinical diagnosis of enthesitis ${ }^{2,11,12}$ (Table
1A), although only the Leeds Enthesitis Index (LEI) has been specifically developed for PsA ${ }^{11}$.

Assessing enthesitis by clinical examination is noninvasive, inexpensive, and relatively fast, and can be conducted as needed without onward referral or access to specialized equipment or facilities. However, clinical identification of enthesitis can be challenging. Assessments are dependent on subjective reports by the patient and physician and do not provide complete information on the extent of entheseal involvement or the presence of subclinical enthesitis ${ }^{9}$. Moreover, tenderness over an entheseal area can also be present in conditions that mimic enthesitis, such as tendinitis or mechanical injury, making a clinical diagnosis subject to false-positive results ${ }^{2}$.

Conventional radiography. Clinical examination can be combined with conventional radiography ${ }^{9}$. Typical radiographic features visible in entheses of patients with PsA include enthesophyte formation, new bone formation, and bony irregularities ${ }^{13}$ (Figure 1B). Radiography is also
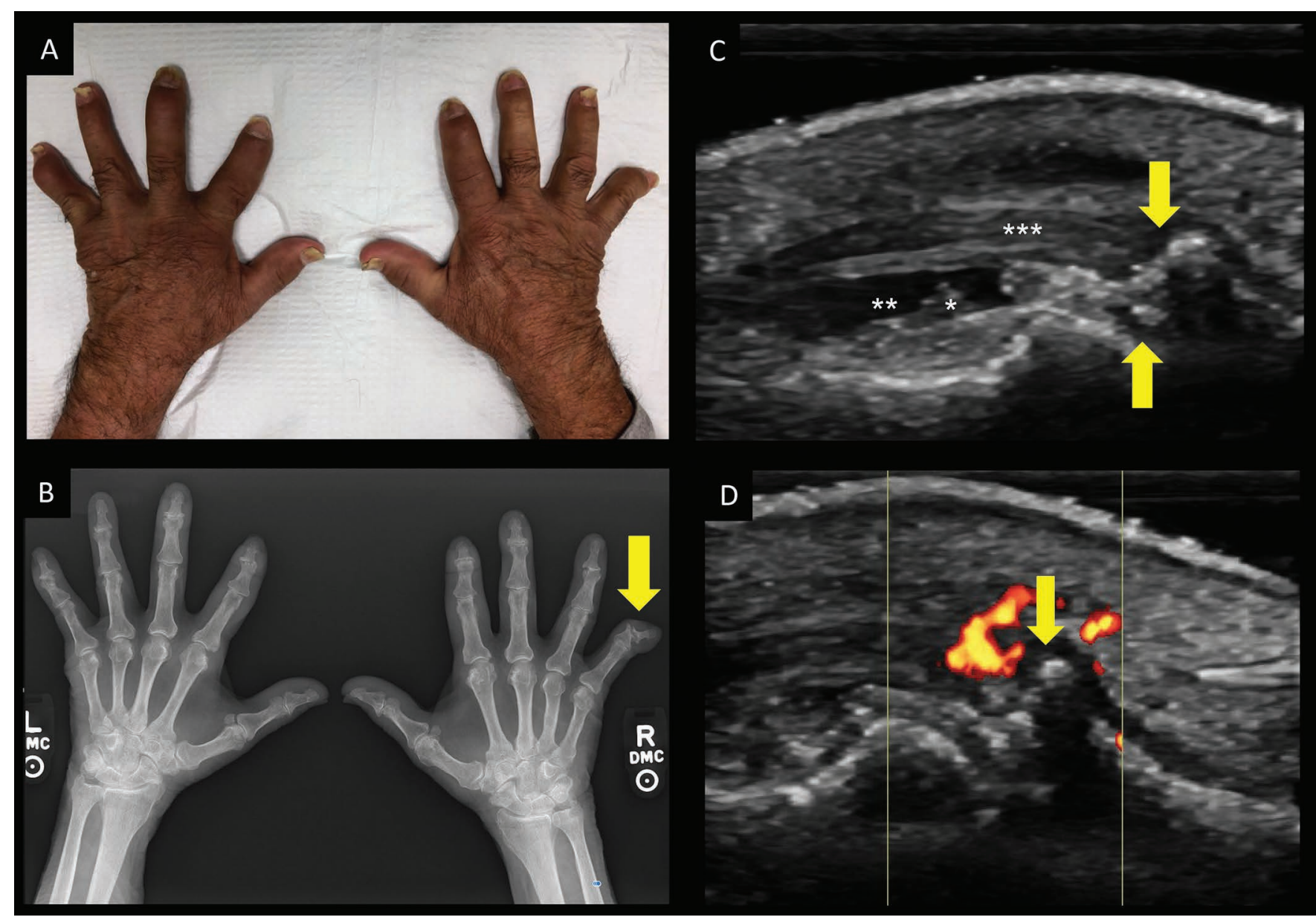

Figure 1. A. Nail changes, dactylitis, and distal interphalangeal joint (DIP) subluxation, as seen during clinical examination. B. Conventional radiographs of the same patient, exhibiting "wispy periostitis," and DIP subluxation (indicated by the arrow). C. Ultrasound providing a longitudinal view of the DIP extensor tendon (indicated by the triple asterisk), showing enthesitis in the hand (extensive cortical irregularity indicated by the downward arrow; DIP joint indicated by the upward arrow). Synovial effusion at the DIP joint can be seen (indicated by the double asterisk) as can synovial hypertrophy (single asterisk). D. Power Doppler ultrasound showing the same area of damage as panel C, with Doppler signal indicating active inflammation around the cortical irregularity.

Personal non-commercial use only. The Journal of Rheumatology Copyright @ 2020 . All rights reserved. 
Table 1A. Clinical indices used in the assessment of enthesitis.

\begin{tabular}{lclcc}
\hline Index Name/ & Originally & No. Sites & Sites & Features \\
Scoring System & Devised for & Examined & Examined & \\
& & & Modality
\end{tabular}

\begin{tabular}{|c|c|c|c|}
\hline $\begin{array}{l}\text { Leeds Enthesitis } \\
\text { Index (LEI)* } 2,11\end{array}$ & PsA & 6 & $\begin{array}{l}\text { Bilateral lateral epicondyles, } \\
\text { medial femoral condyles, } \\
\text { and Achilles tendon insertions }\end{array}$ \\
\hline
\end{tabular}

Only index specifically developed for PsA; has been used in several None and Achilles tendon insertions

Spondyloarthritis
Research
Consortium of
Canada (SPARCC) index*2,11

The Maastricht AS Ankylosing Spondylitis Enthesis Score (MASES)* 2,11,12
PsA trials - developed by clinical identification of the most frequent enthesitis sites

Physical examination measuring tenderness as either present (1) or absent (0) at each site, resulting in an overall score of 0-6

Higher count indicates greater enthesitis burden

Most reliable index for PsA; correlates most closely with disease activity compared with MASES and SPARCC

Assessment sites based on power Doppler US in SpA and MRI studies in None

AS. Most common sites for enthesitis were identified

Physical examination measuring tenderness as either present (1)

or absent (0) at each site, resulting in an overall score of 0-16

Higher count indicates greater enthesitis burden

Modified versions measuring 6-8 more commonly involved sites have

shown greater responsiveness

Not validated for use in PsA, although has been tested in this patient population

Developed from the Mander/Newcastle Enthesitis Index (most

None comprehensive index for AS, with 66 clinically accessible enthesis sites) Most specific and sensitive sites were selected to reduce assessment time Physical examination measuring tenderness as either present (1) or absent (0) at each site, resulting in an overall score of 0-13

Higher count indicates greater enthesitis burden

Not validated for use in PsA, although a PsA-modified version has been developed

*LEI, MASES, and SPARCC have all been used in trials of PsA ${ }^{2}$.

particularly useful for monitoring syndesmophytes in spinal entheses ${ }^{14}$.

The cost of taking conventional radiographs is low, as is the need for specialized facilities. However, radiographs do not reveal inflammation in soft tissue structures; hence, only damage associated with chronic enthesitis, and not early disease, is visible $e^{2,13,15}$. Therefore, the usefulness of radiography for diagnosing enthesitis in early PsA is limited ${ }^{2,13,15}$. Similarly, the benefits of using radiography to monitor enthesitis in peripheral sites are limited. These limitations have highlighted the need for more sensitive imaging techniques in the assessment of enthesitis.

Ultrasound (US). US is widely used because it is inexpensive and accessible, is nonionizing and noninvasive, and produces real-time images, allowing documentation of clinical information at the point of care with minimal risk of harm to the patient ${ }^{2,16}$. Most published US studies in PsA have focused on the entheses of the lower extremities; however, more recent scoring systems have incorporated upper-extremity entheses, recognizing the confounding factors of body weight and biomechanics on the lower-extremity entheses ${ }^{17}$. Greyscale US (Figures 1C, 1D, 2A, and 2B) can detect both acute (e.g., increasing thickness, hypoechogenicity) and chronic inflammation or changes (e.g., erosions, enthesophytes $)^{18}$. These components, including chronic changes, have recently been reported to be part of the definition of enthesitis ${ }^{19,20}$ and may be important for differentiating patients with PsA from those without disease $^{20}$. A sonographic Doppler signal (Figure 1D) can be used to detect active inflammation, evidenced by abnormal vascularization $^{20}$ (Figure $2 \mathrm{C}$ and $2 \mathrm{D}$ ). It has also proven useful in identifying subclinical involvement of entheses prior to development of symptoms ${ }^{20,21,22}$. A consensus definition of enthesitis by US assessment was recently proposed by the OMERACT US Working Group (UWG) and states that enthesitis is a hypoechoic and/or thickened insertion of the tendon within $2 \mathrm{~mm}$ of the bony cortex, which exhibits a Doppler signal if active, with possible erosions and enthesophytes/calcifications as signs of structural damage ${ }^{19,22}$. However, defining enthesitis as being within $2 \mathrm{~mm}$ of the bony cortex remains an area of active debate, with the GRAPPA UWG maintaining that the enthesis boundary could also extend beyond this cutoff or to within the adjacent bursa $^{20}$. This is consistent with the concept of the "enthesis organ" or the "synovio-entheseal complex" that comprises more than the joint insertion site alone and includes the nearby synovium ${ }^{23}$; thus, the OMERACT UWG's current definition may not fully identify all the inflammatory changes due to enthesitis.

Several scoring systems have been devised for

Personal non-commercial use only. The Journal of Rheumatology Copyright @ 2020 . All rights reserved. 


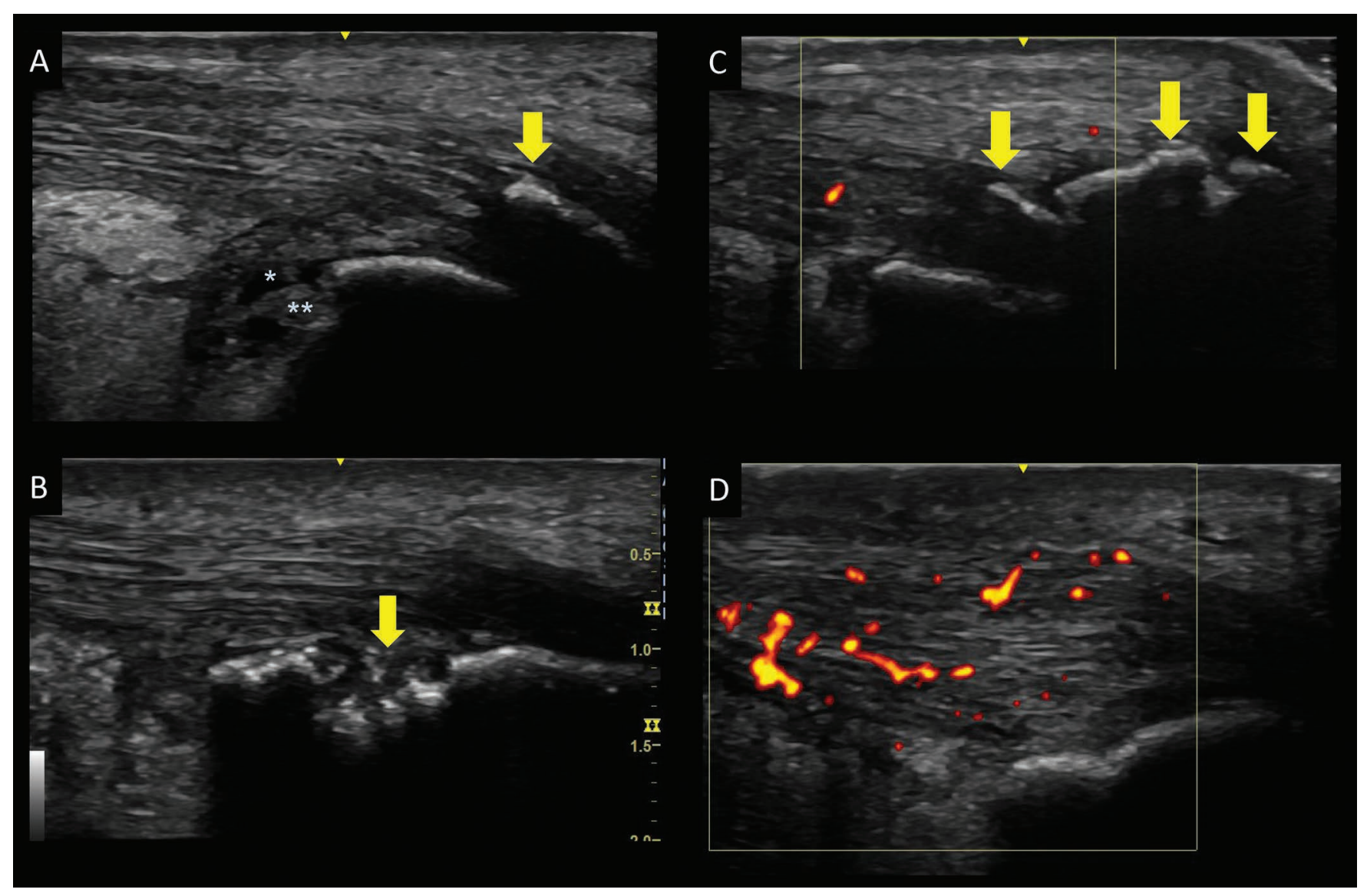

Figure 2. A. A large enthesophyte (as indicated by the arrow) as well as significant retrocalcaneal bursitis and bursal synovitis (as indicated by the double asterisk). Retrocalcaneal bursal effusion can also be seen (as indicated by the single asterisk). B. Achilles enthesitis that includes large erosions (as indicated by the arrow) and cortical irregularities. C. Significant bone proliferation of the calcaneus (indicated by the arrows), as well as tendon hypoechogenicity, thickening, and loss of fibrillar echotexture. D. Active inflammation as indicated by Doppler signal, located at the distal portion of the Achilles tendon.

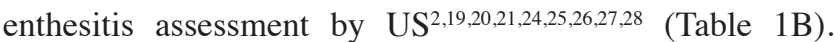
The OMERACT UWG Enthesitis Score was developed in conjunction with the consensus definition of enthesitis. This scoring system emphasizes defining lesions at the enthesis as being within $2 \mathrm{~mm}$ of the cortical bone and those outside the enthesis as being in the tendon or bursa, as well as the benefit of scoring each component as present or absent ${ }^{19}$ (Table 1B). The GRAPPA UWG is also working on a scoring system designed specifically to assess enthesitis in PsA for diagnostic purposes ${ }^{20}$. The GRAPPA UWG identified 5 lesions and 6 entheseal sites (Table 1B) as being critical for identifying patients with PsA and is currently working on validating and finalizing the scoring method ${ }^{20}$.

Other US scoring methods have been used to assess enthesitis for diagnosis and entheseal response to treatment (Table 1B). Although most scoring systems have a reasonable level of reliability and sensitivity, they were developed and evaluated in spondyloarthritis (SpA) rather than PsA specifically ${ }^{7}$. Additionally, most of these approaches also have a strong focus on entheses in the lower extremities of the body, which may be confounded by mechanical changes caused by aging, physical activity, and obesity ${ }^{7,29}$.
Some limitations associated with US in the assessment of enthesitis include its inability to identify any intraosseous abnormalities associated with active enthesitis ${ }^{30}$ and the lack of guidelines regarding Doppler settings for enthesitis imaging. Further difficulties involve standardization of settings on different machines ${ }^{9}$ and weak signals and artifacts due to the small number of blood vessels in entheses and proximity to bone ${ }^{21}$; however, visualizing avascular fibrocartilage at entheseal sites with US is possible ${ }^{31}$.

Magnetic resonance imaging (MRI). MRI is a powerful nonionizing imaging technique that can be used to evaluate axial or peripheral entheses ${ }^{2,15}$. MRI sequences for enthesitis evaluation typically are $\mathrm{T} 1$ weighted, T2 weighted with fat suppression or short-tau inversion recovery, or T1 weighted with fat suppression after contrast administration ${ }^{30}$. Because of its ability to detect small differences in water content between adjacent tissue types, MRI can detect early signs of enthesitis that are not visible using radiography ${ }^{15}$. It can provide high-resolution evidence of soft tissue abnormalities such as thickening of tendons and ligaments, joint effusions and inflammation, bone erosions, enthesophytes, and intraosseous bone marrow edema ${ }^{30}$ (Figure $3 \mathrm{~A}-3 \mathrm{C}$ ).

Personal non-commercial use only. The Journal of Rheumatology Copyright @ 2020 . All rights reserved. 
Table 1B. Ultrasound scoring scales used in the assessment of enthesitis.

\begin{tabular}{|c|c|c|c|c|c|}
\hline $\begin{array}{l}\text { Index Name/ } \\
\text { Scoring System }\end{array}$ & $\begin{array}{l}\text { Originally } \\
\text { Devised for }\end{array}$ & $\begin{array}{l}\text { No. Sites } \\
\text { Examined }\end{array}$ & $\begin{array}{c}\text { Sites } \\
\text { Examined }\end{array}$ & Features & $\begin{array}{l}\text { Imaging } \\
\text { Modality }\end{array}$ \\
\hline $\begin{array}{l}\text { OMERACT } \\
\text { Ultrasound } \\
\text { Working } \\
\text { Group }^{19}\end{array}$ & SpA and PsA & $\begin{array}{l}4 \text { (3 lower } \\
\text { limbs, } 1 \text { upper } \\
\text { body })\end{array}$ & $\begin{array}{l}\text { Superior and inferior } \\
\text { poles of the patella, } \\
\text { calcaneal insertion of } \\
\text { Achilles tendon; lateral } \\
\text { condyle of the elbow }\end{array}$ & $\begin{array}{l}\text { Developed to monitor changes in inflammatory lesions following } \\
\text { treatment } \\
\text { Evaluates global enthesis involvement in an individual patient } \\
\text { Each enthesis evaluated (yes/no basis) for } 7 \text { elementary components } \\
\text { (hypoechogenicity, increased thickness, enthesophyte, calcification, } \\
\text { bone erosion, bone irregularity, and PD) } \\
\text { Next steps will be to weigh the different inflammatory components } \\
\text { and test their sensitivity to change }\end{array}$ & $\begin{array}{c}\text { Greyscale } \\
\text { and PD }\end{array}$ \\
\hline $\begin{array}{l}\text { The GRAPPA } \\
\text { Ultrasound } \\
\text { Working Group }^{20,24}\end{array}$ & PsA & $\begin{array}{c}6 \text { (4 lower limbs, } \\
2 \text { upper body) }\end{array}$ & $\begin{array}{l}\text { Patellar ligament insertions } \\
\text { into distal patella } \\
\text { and tibial tuberosity, } \\
\text { Achilles tendon, plantar } \\
\text { fascia; supraspinatus, } \\
\text { lateral epicondyle }\end{array}$ & $\begin{array}{l}\text { Developed to allow for early diagnosis of PsA } \\
\text { Evaluates global enthesis involvement in an individual patient } \\
\text { Assesses } 5 \text { elementary lesions (hypoechogenicity, thickening, } \\
\text { enthesophyte, erosions, and Doppler signal) of } 6 \text { entheseal sites } \\
\text { Identified } 6 \text { entheseal sites important for distinguishing patients } \\
\text { with PsA from those without the disease: patellar ligament } \\
\text { insertions into the distal patella and tibial tuberosity, Achilles tendon } \\
\text { and plantar fascia insertions into the calcaneus, common extensor } \\
\text { tendon insertion into the lateral epicondyle, and supraspinatus } \\
\text { insertion into the superior facet of the humerus } \\
\text { Aims to distinguish patients with PsA from age- and sex-matched } \\
\text { healthy controls, and monitor response to treatment }\end{array}$ & $\begin{array}{c}\text { Greyscale } \\
\text { and PD }\end{array}$ \\
\hline $\begin{array}{l}\text { Glasgow } \\
\text { Ultrasound } \\
\text { Enthesis Scoring S }\end{array}$ & $\begin{array}{r}\text { SpA } \\
\text { System } \\
2,21,25\end{array}$ & $\begin{array}{l}5 \text { (lower } \\
\text { limb only) } \\
\text { Ach }\end{array}$ & $\begin{array}{l}\text { Quadriceps tendon, } \\
\text { patellar ligament } \\
\text { (proximal and distal), } \\
\text { ailles tendon, plantar aponeurosis }\end{array}$ & $\begin{array}{l}\text { Developed for diagnosis of SpA } \\
\text { Assesses } 18 \text { features of } 5 \text { entheses - grading individual enthesis involvem } \\
\text { First scoring system to be published (2002) }\end{array}$ & $\begin{array}{l}\text { Greyscale } \\
\text { nent }\end{array}$ \\
\hline $\begin{array}{l}\text { Sonographic } \\
\text { Enthesitis Index }{ }^{26}\end{array}$ & AS & $\begin{array}{l}5 \text { (lower } \\
\text { limb only) } \\
\\
\text { Ach }\end{array}$ & $\begin{array}{l}\text { Quadriceps tendon, } \\
\text { patellar tendon } \\
\text { (proximal and distal), } \\
\text { iilles tendon, plantar aponeurosis }\end{array}$ & $\begin{array}{l}\text { Developed for monitoring disease activity and entheseal } \\
\text { response to treatment } \\
\text { Evaluates global enthesis involvement in an individual patient } \\
\text { Differentiates between inflammatory and structural damage } \\
\text { Does not differentiate between involvement of enthesis, body } \\
\text { of tendon, and bursa }\end{array}$ & Greyscale \\
\hline
\end{tabular}

AS: ankylosing spondylitis; GRAPPA: Group for Research and Assessment of Psoriasis and Psoriatic Arthritis; MRI: magnetic resonance imaging; OMERACT: Outcome Measures in Rheumatology; PD: power Doppler; PsA: psoriatic arthritis; SpA: spondyloarthritis; US: ultrasound.

The PsA MRI Score (PsAMRIS) is the most studied scoring system for measuring destructive and inflammatory changes in the hands and feet in PsA; however, it is not specific for assessing enthesitis ${ }^{32,33}$. PsAMRIS was devised by the OMERACT MRI Working Group and has been shown to have good intrareader and interreader reliability ${ }^{29,33}$. PsAMRIS includes measures of synovitis, tenosynovitis, periarticular inflammation, bone marrow edema, bone erosion, and bone proliferation ${ }^{32}$. Further application of PsAMRIS in randomized controlled trials of PsA is warranted ${ }^{29}$.
Given the lack of MRI scoring systems for evaluating enthesitis, the OMERACT MRI in Arthritis Working Group recently developed the Heel Enthesitis Scoring System (HEMRIS) for use in patients with SpA or PsA ${ }^{34}$. Both inflammatory and structural MRI findings were included, with HEMRIS showing good interreader agreement for status scores and for changes in inflammatory variables over time. Notably, the heel enthesitis score was especially reliable when the mean score of 2 readers was used, an approach that is typically used in clinical trials. Overall, HEMRIS is

Personal non-commercial use only. The Journal of Rheumatology Copyright () 2020. All rights reserved. 


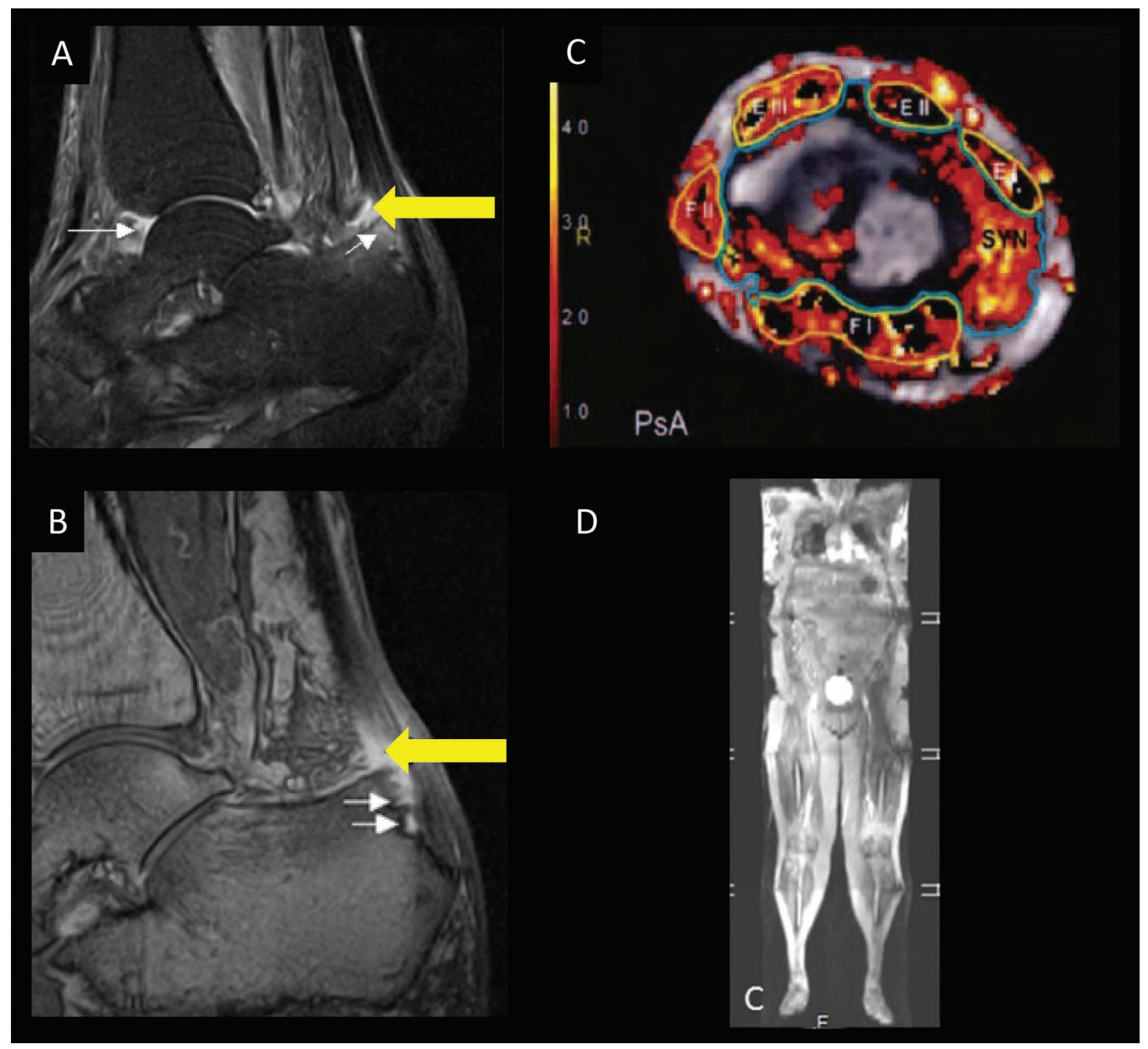

Figure 3. A. Short T1 inversion recovery magnetic resonance imaging (MRI) showing high signal intensity at the Achilles tendon insertion (enthesitis, indicated by the yellow arrow) and bone marrow edema (short thin arrow). Long thin arrow shows high signal intensity in the synovium of the ankle joint (synovitis). Image reproduced with permission from McQueen F, et al. Arthritis Res Ther 2006;8:207. (C) BioMed Central Ltd 2006. B. T1-weighted, contrast-enhanced MRI showing inflammation at enthesis (indicated by the yellow arrow) and bone erosion at the tendon insertion (short thin arrows). Image reproduced with permission from McQueen F, et al. Arthritis Res Ther. 2006;8:207. (C) BioMed Central Ltd 2006. C. Dynamic contrast-enhanced MRI technology superimposed on an axial T1-weighted dynamic MRI of the wrist showing tenosynovitis. The wrist synovial membrane is outlined in blue (joint synovial membrane compartment indicated by SYN) and regions around the tendon sheaths are yellow (first to third extensor compartment indicated by EI-III, first and second flexor compartment indicated by FI-II). Reprinted with permission from The Journal of Rheumatology, Cimmino MA, et al. J Rheumatol Suppl. 2012 Jul;89:44-8. All rights reserved. D. Whole-body MRI enables visualization of multiple potential sites of enthesitis in 1 scan but at a lower resolution than conventional MRI. Østergaard M, et al. Best Pract Res Clin Rheumatol 2016;30:624-37. Copyright 2008, reprinted with permission from Elsevier.

a promising tool, and validation in clinical trials will be important.

Whole-body (WB) MRI is a novel approach that allows visualization of the entire body in 1 examination but has lower image resolution than conventional MRI ${ }^{33}$ (Figure 3D). A proof-of-concept study showed that enthesitis was the most common pathology detected by WB-MRI and that significantly more locations of enthesitis were identified with WB-MRI than with clinical examination ${ }^{35}$. GOLMePsA, an ongoing trial of golimumab and methotrexate in early PsA, is expected to provide data on the role of WB-MRI as an outcome measure by assessing the effect of treatment

Personal non-commercial use only. The Journal of Rheumatology Copyright @ 2020 . All rights reserved. 
on inflammation as visualized using WB-MRI and US ${ }^{36}$. However, WB-MRI carries some limitations. For instance, subtle enthesitis can sometimes only be visualized following administration of contrast media ${ }^{35}$. Additionally, agreement between WB-MRI and clinical examination is often $<50 \%$, and readability and reproducibility of WB-MRI for distal peripheral joints are low because of poor resolution. Thus, further clarity surrounding the generalizability of this technique for detecting enthesitis is required ${ }^{37,38}$.

The OMERACT MRI Working Group has taken the first steps toward standardizing the process of WB-MRI, including image acquisition and definitions of key pathologies and has developed a preliminary OMERACT scoring system for the assessment of inflammatory arthritis using WB-MRI ${ }^{39}$. The GRAPPA MRI Working Group has also been investigating outcome measures for trials in PsA and is proposing to conduct a longitudinal, multicenter, and preferably randomized treatment study in patients with active PsA that will assess WB-MRI of peripheral and axial joints and entheses according to the OMERACT recommendations ${ }^{24}$. The study will also incorporate assessment of feet and hands using PsAMRIS, as well as knees and hips using Knee and Hip Inflammation MRI Scoring Systems ${ }^{24}$.

Newer MRI techniques have also been developed. Diffusion-weighted imaging MRI is a technique based on the Brownian motion of water, which is reduced in inflammation $^{15}$. Diffusion-weighted imaging MRI provided good differentiation between active and inactive ankylosing spondylitis; however, enthesitis and synovitis were not evaluated, and further studies are needed to assess the usefulness of this technique ${ }^{40}$. Ultrashort echo time MRI (UTE MRI) has also been investigated because it allows changes at the entheses to be viewed at higher resolution and earlier than conventional $\mathrm{MRI}^{41}$. One study has shown that UTE MRI can be used for morphological and quantitative evaluation of entheses in patients with $\mathrm{PsA}^{41}$.

Despite the benefits described above, MRI has many limitations. It is expensive and time consuming and often requires referral to specialist facilities. MRI examinations are not suitable for patients with claustrophobia, pacemakers, or metal implants ${ }^{15}$. Further, MRI may result in adverse effects from the administration of contrast media (e.g., nephrogenic systemic fibrosis in patients with renal insufficiency, allergic reaction). MRI cannot always exclude enthesitis; owing to limited water accumulation, MRI signals are often low in structures that make up the entheses ${ }^{42}$. Therefore, MRI alone may not be sufficient to consistently detect clinically meaningful changes in enthesitis ${ }^{43}$. For instance, in the HEEL study of etanercept versus placebo in patients with SpA and heel enthesitis, significant improvement was observed with etanercept by clinical assessment using patient's global assessment but not by $\mathrm{MRI}^{43}$. However, the trial size was small and only calcaneal bone marrow edema was consid$\operatorname{ered}^{43}$. The development and use of composite scoring systems such as HEMRIS may improve the utility of MRI in PsA.

Computed tomography $(C T)$ and scintigraphy. CT has high spatial resolution and can detect structural changes, such as erosions. However, standard-resolution CT imaging is limited in its ability to detect synovial inflammation owing to poor iodine contrast resolution, and longitudinal data regarding its usefulness in diagnosing and monitoring enthesitis are lacking ${ }^{44}$. Dual-energy CT iodine mapping, which improves iodine contrast resolution, has a higher spatial resolution than MRI and has shown promise in detecting inflammatory lesions, especially lesions in small joints (e.g., distal interphalangeal joints ${ }^{45,46}$. Additional studies are needed to determine the role of this technique in the diagnosis of early-stage PsA and assessment of therapeutic effects. Positron emission tomography (PET)/ CT using 18F-fluorodeoxyglucose (FDG) may also be of value given that a retrospective study found high accumulation of FDG in the entheses of patients with $\mathrm{SpA}^{47}$. In that study, PET/CT-FDG had a higher sensitivity for evaluating enthesitis than MRI; however, this was a small-scale, retrospective study, and further studies are needed.

Scintigraphy can also be used in PsA; radioisotopes that selectively bind to specific tissue types are taken internally, and the radiation they emit is recorded by external detectors. However, because of a lack of specificity, scintigraphy has been largely replaced by US and MRI ${ }^{35,44}$. Immunoscintigraphy aims to improve on the current technique by using a radiolabeled tumor necrosis factor (TNF) inhibitor [certolizumab pegol (CZP)] to detect TNF- $\alpha-$ driven inflammation in $v i v o^{48}$. A recent study found that peripheral and axial inflammation could be detected in patients who received intravenous injections of radiolabeled $\mathrm{CZP}$, with a strong correlation with therapy response: joints with no uptake of the tracer were more likely to remain tender despite treatment with $\mathrm{CZP}^{48}$. These newer imaging modalities are promising but carry the limitation of exposing patients to radiation. Further evaluation of these modalities is necessary.

\section{Using imaging to monitor treatment response in clinical trials}

Multiple clinical trials have assessed the efficacy of biologic and small-molecule drugs in the treatment of enthesitis in $\mathrm{PsA}^{2}$. However, the number of patients within these trials who have enthesitis at baseline varies widely $(24-83 \%)^{2}$. That is because patients with PsA are generally enrolled into clinical trials of biologic agents based on the CASPAR criteria, which do not mandate the presence of enthesitis to date, very few trials have listed enthesitis as an inclusion criterion.

Overall, there is a need for studies that assess the effect of treatment on enthesitis and use imaging as an objective measure. Based on a search of ClinicalTrials.gov for studies

Personal non-commercial use only. The Journal of Rheumatology Copyright @ 2020 . All rights reserved. 
that required $\geq 1$ entheseal site at baseline and used imaging to assess response to treatment, only 2 studies have been designed to date and are currently ongoing.

The ACHILLES trial (NCT02771210) ${ }^{49}$ is an ongoing phase III, randomized, quadruple-blind study investigating the efficacy of secukinumab in the resolution of Achilles tendon enthesitis, including effects on inflammation as assessed by MRI, in PsA and axial SpA (axSpA). The primary outcome measure is the proportion of patients with resolution of Achilles tendon enthesitis at Week 24 as assessed by the LEI; secondary outcome measures include the percentage of patients with improvement of bone marrow edema as assessed by PsAMRIS. Key inclusion criteria are active PsA or axSpA and MRI-positive heel enthesitis at baseline.

The ULTIMATE trial (NCT02662985) ${ }^{50}$ is an ongoing phase III, randomized, triple-blind study investigating the sensitivity of US to describe the time course of response to secukinumab in joint synovitis and enthesitis in PsA. The primary outcome measure is the difference between secukinumab and placebo in terms of joint synovitis at Week 12 as assessed by the PDUS Global OMERACT-EULAR Synovitis Score; secondary outcome measures include improvement in enthesitis at Week 12 as assessed by the Spondyloarthritis Research Consortium of Canada Enthesitis Index. Some key inclusion criteria are active PsA and $\geq 1$ clinically involved enthesitis site at baseline.

Results of these trials are anticipated to provide much-needed data on the validation of new imaging techniques and scoring scales in the monitoring of enthesitis during clinical trials.

\section{Conclusion}

Early diagnosis and treatment of PsA may prevent disease progression and structural damage ${ }^{8}$. Given that enthesitis is a marker of PsA and an indicator of disease severity, early identification and treatment of enthesitis in patients with PsA is of great importance. Historically, enthesitis has been assessed using a combination of clinical examination and conventional radiography. However, the usefulness of these techniques in the early identification of enthesitis is limited. Newer imaging techniques have since been developed ${ }^{21,30}$ that allow for direct visualization of the enthesis and related structures and offer the potential to systematically assess enthesitis earlier in the disease course, possibly leading to improved patient outcomes.

Despite this progress, there is currently no gold standard technique to detect enthesitis ${ }^{9}$. Additionally, more research into the utility of US and MRI for the diagnosis and monitoring of enthesitis in PsA is required. Standardized definitions, imaging techniques, and operator protocols are needed, as are validated scoring systems. Clinical trials that focus on the treatment of enthesitis and use imaging to assess treatment response will allow the efficacy of new therapeutic agents to be assessed and compared more accurately. As technical improvements in imaging are realized, different imaging tools and scoring systems may be preferred for entheses in the lower limbs compared with those in non-weight-bearing, smaller structures. Overall, available data highlight the importance of incorporating imaging modalities in the clinical assessment and management of patients with PsA.

\section{ACKNOWLEDGMENT}

Medical writing support was provided by Victoria Kinsley, PhD (SciMentum), and Karen Chinchilla, PhD (ArticulateScience LLC), funded by Novartis Pharmaceuticals Corp., East Hanover, New Jersey, in accordance with Good Publication Practice (GPP3) guidelines (www.ismpp.org/ gpp3).

\section{ONLINE SUPPLEMENT}

Supplementary material accompanies the online version of this article.

\section{REFERENCES}

1. Coates LC, Helliwell PS. Psoriatic arthritis: state of the art review. Clin Med 2017; 17:65-70.

2. Kaeley GS, Eder L, Aydin SZ, Gutierrez M, Bakewell C. Enthesitis: a hallmark of psoriatic arthritis. Semin Arthritis Rheum 2018; 48:35-53.

3. Veale DJ, Fearon U. What makes psoriatic and rheumatoid arthritis so different? RMD Open 2015;1:e000025.

4. McGonagle D, Conaghan PG, Emery P. Psoriatic arthritis: a unified concept twenty years on. Arthritis Rheum 1999;42:1080-6.

5. Taylor W, Gladman D, Helliwell P, Marchesoni A, Mease P, Mielants H, et al; CASPAR Study Group. Classification criteria for psoriatic arthritis: development of new criteria from a large international study. Arthritis Rheum 2006;54:2665-73.

6. Coates LC, Kavanaugh A, Mease PJ, Soriano ER, Laura Acosta-Felquer M, Armstrong AW, et al. Group for Research and Assessment of Psoriasis and Psoriatic Arthritis 2015 treatment recommendations for psoriatic arthritis. Arthritis Rheumatol 2016;68:1060-71

7. Elalouf O, Bakirci Ureyen S, Touma Z, Anderson M, Kaeley GS, Aydin SZ, et al. Psoriatic arthritis sonographic enthesitis instruments: a systematic review of the literature. J Rheumatol 2019;46:43-56.

8. Haroon M, Gallagher P, Fitzgerald O. Diagnostic delay of more than 6 months contributes to poor radiographic and functional outcome in psoriatic arthritis. Ann Rheum Dis 2015;74:1045-50.

9. Micu MC, Fodor D. Concepts in monitoring enthesitis in patients with spondylarthritis--the role of musculoskeletal ultrasound. Med Ultrason 2016;18:82-9.

10. Weiss PF. Diagnosis and treatment of enthesitis-related arthritis. Adolesc Health Med Ther 2012;2012:67-74.

11. Mease PJ. Measures of psoriatic arthritis: Tender and Swollen Joint Assessment, Psoriasis Area and Severity Index (PASI), Nail Psoriasis Severity Index (NAPSI), Modified Nail Psoriasis Severity Index (mNAPSI), Mander/Newcastle Enthesitis Index (MEI), Leeds Enthesitis Index (LEI), Spondyloarthritis Research Consortium of Canada (SPARCC), Maastricht Ankylosing Spondylitis Enthesis Score (MASES), Leeds Dactylitis Index (LDI), Patient Global for Psoriatic Arthritis, Dermatology Life Quality Index (DLQI), Psoriatic Arthritis Quality of Life (PsAQOL), Functional Assessment of Chronic Illness Therapy-Fatigue (FACIT-F), Psoriatic Arthritis Response Criteria (PsARC), Psoriatic Arthritis Joint Activity Index (PsAJAI), Disease Activity in Psoriatic 
Arthritis (DAPSA), and Composite Psoriatic Disease Activity Index (CPDAI). Arthritis Care Res 2011;63 Suppl 11:S64-85.

12. Mease PJ, Van den Bosch F, Sieper J, Xia Y, Pangan AL, Song IH. Performance of 3 enthesitis indices in patients with peripheral spondyloarthritis during treatment with adalimumab. J Rheumatol 2017;44:599-608.

13. McGonagle D. Imaging the joint and enthesis: insights into pathogenesis of psoriatic arthritis. Ann Rheum Dis 2005;64 Suppl 2:ii58-60.

14. Watad A, Eshed I, McGonagle D. Lessons learned from imaging on enthesitis in psoriatic arthritis. Isr Med Assoc J 2017;19:708-11

15. Ran J, Morelli JN, Xie R, Zhang X, Liang X, Liu X, et al. Role for imaging in spondyloarthritis. Q J Nucl Med Mol Imaging 2017;61:271-82.

16. Phenix CP, Togtema M, Pichardo S, Zehbe I, Curiel L. High intensity focused ultrasound technology, its scope and applications in therapy and drug delivery. J Pharm Pharm Sci 2014;17:136-53.

17. Zabotti A, Idolazzi L, Batticciotto A, De Lucia O, Scire CA, Tinazzi I, et al. Enthesitis of the hands in psoriatic arthritis: an ultrasonographic perspective. Med Ultrason 2017;19:438-43.

18. D'Agostino MA. Enthesitis detection by ultrasound: where are we now? Clin Exp Rheumatol 2018;36 Suppl 114:127-30.

19. Balint PV, Terslev L, Aegerter P, Bruyn GAW, Chary-Valckenaere I, Gandjbakhch F, et al; OMERACT Ultrasound Task Force members Reliability of a consensus-based ultrasound definition and scoring for enthesitis in spondyloarthritis and psoriatic arthritis: an OMERACT US initiative. Ann Rheum Dis 2018;77:1730-5.

20. Tom S, Zhong Y, Cook RJ, Aydin SZ, Kaeley GS, Eder L. Development of a preliminary ultrasonographic enthesitis score in psoriatic arthritis - GRAPPA Ultrasound Working Group. J Rheumatol 2019;46:384-90.

21. Delle Sedie A, Riente L. Psoriatic arthritis: what ultrasound can provide us. Clin Exp Rheumatol 2015;33 (5 Suppl 93):S60-5.

22. Terslev L, Naredo E, Iagnocco A, Balint PV, Wakefield RJ, Aegerter $\mathrm{P}$, et al; Outcome Measures in Rheumatology Ultrasound Task Force. Defining enthesitis in spondyloarthritis by ultrasound: results of a Delphi process and of a reliability reading exercise. Arthritis Care Res 2014;66:741-8.

23. McGonagle D, Lories RJ, Tan AL, Benjamin M. The concept of a "synovio-entheseal complex" and its implications for understanding joint inflammation and damage in psoriatic arthritis and beyond. Arthritis Rheum 2007;56:2482-91.

24. Eder L, Aydin SZ, Kaeley GS, Maksymowych WP, Østergaard M. Options for assessing joints and entheses in psoriatic arthritis by ultrasonography and magnetic resonance imaging: how to move forward. J Rheumatol Suppl. 2018 Jun;94:44-7.

25. Balint PV, Kane D, Wilson H, McInnes IB, Sturrock RD. Ultrasonography of entheseal insertions in the lower limb in spondyloarthropathy. Ann Rheum Dis 2002;61:905-10.

26. Alcalde M, Acebes JC, Cruz M, Gonzalez-Hombrado L, Herrero-Beaumont G, Sanchez-Pernaute O. A sonographic enthesitic index of lower limbs is a valuable tool in the assessment of ankylosing spondylitis. Ann Rheum Dis 2007;66:1015-9.

27. de Miguel E, Cobo T, Munoz-Fernandez S, Naredo E, Uson J, Acebes JC, et al. Validity of enthesis ultrasound assessment in spondyloarthropathy. Ann Rheum Dis 2009;68:169-74.

28. D'Agostino MA, Said-Nahal R, Hacquard-Bouder C, Brasseur JL, Dougados M, Breban M. Assessment of peripheral enthesitis in the spondylarthropathies by ultrasonography combined with power Doppler: a cross-sectional study. Arthritis Rheum 2003;48:523-33.

29. Østergaard M, Eder L, Christiansen SN, Kaeley GS. Imaging in the diagnosis and management of peripheral psoriatic arthritis-The clinical utility of magnetic resonance imaging and ultrasonography. Best Pract Res Clin Rheumatol 2016;30:624-37.

30. Eshed I, Bollow M, McGonagle DG, Tan AL, Althoff CE,
Asbach P, et al. MRI of enthesitis of the appendicular skeleton in spondyloarthritis. Ann Rheum Dis 2007;66:1553-9.

31. Aydin SZ, Bas E, Basci O, Filippucci E, Wakefield RJ, Celikel $\mathrm{C}$, et al. Validation of ultrasound imaging for Achilles entheseal fibrocartilage in bovines and description of changes in humans with spondyloarthritis. Ann Rheum Dis 2010;69:2165-8.

32. Glinatsi D, Bird P, Gandjbakhch F, Mease PJ, Boyesen P, Peterfy CG, et al. Validation of the OMERACT Psoriatic Arthritis Magnetic Resonance Imaging Score (PsAMRIS) for the hand and foot in a randomized placebo-controlled trial. J Rheumatol 2015;42:2473-9.

33. Poggenborg RP, Sørensen IJ, Pedersen SJ, Østergaard M. Magnetic resonance imaging for diagnosing, monitoring and prognostication in psoriatic arthritis. Clin Exp Rheumatol 2015;5 Suppl 93:S66-9.

34. Mathew AJ, Krabbe S, Eshed I, Gandjbakhch F, Bird P, Pedersen SJ, et al. The OMERACT MRI in Enthesitis Initiative: definitions of key pathologies, suggested MRI sequences, and a novel Heel Enthesitis Scoring System. J Rheumatol 2019;46:1232-8.

35. Weckbach S, Schewe S, Michaely HJ, Steffinger D, Reiser MF, Glaser C. Whole-body MR imaging in psoriatic arthritis: additional value for therapeutic decision making. Eur J Radiol 2011; 77:149-55.

36. De Marco G, Helliwell P, McGonagle D, Emery P, Coates LC, Hensor EMA, et al. The GOLMePsA study protocol: an investigator-initiated, double-blind, parallel-group, randomised, controlled trial of GOLimumab and methotrexate versus methotrexate in early diagnosed psoriatic arthritis using clinical and whole body MRI outcomes. BMC Musculoskelet Disord 2017; 18:303.

37. Poggenborg RP, Eshed I, Østergaard M, Sørensen IJ, Møller JM, Madsen OR, et al. Enthesitis in patients with psoriatic arthritis, axial spondyloarthritis and healthy subjects assessed by 'head-to-toe' whole-body MRI and clinical examination. Ann Rheum Dis 2015;74:823-9.

38. Poggenborg RP, Pedersen SJ, Eshed I, Sørensen IJ, Møller JM, Madsen OR, et al. Head-to-toe whole-body MRI in psoriatic arthritis, axial spondyloarthritis and healthy subjects: first steps towards global inflammation and damage scores of peripheral and axial joints. Rheumatology 2015;54:1039-49.

39. Østergaard M, Eshed I, Althoff CE, Poggenborg RP, Diekhoff $\mathrm{T}$, Krabbe $\mathrm{S}$, et al. Whole-body magnetic resonance imaging in inflammatory arthritis: systematic literature review and first steps toward standardization and an OMERACT scoring system. J Rheumatol 2017;44:1699-705.

40. Zhao YH, Cao YY, Zhang Q, Mei YJ, Xiao JJ, Hu SY, et al. Role of diffusion-weighted and contrast-enhanced magnetic resonance imaging in differentiating activity of ankylosing spondylitis. Chin Med J 2017;130:1303-8.

41. Chen B, Zhao Y, Cheng X, Ma Y, Chang EY, Kavanaugh A, et al. Three-dimensional ultrashort echo time cones (3D UTE-Cones) magnetic resonance imaging of entheses and tendons. Magn Reson Imaging 2018;49:4-9.

42. Kehl AS, Corr M, Weisman MH. Enthesitis: new insights into pathogenesis, diagnostic modalities, and treatment. Arthritis Rheumatol 2016;68:312-22.

43. Dougados M, Combe B, Braun J, Landewe R, Sibilia J, Cantagrel A, et al. A randomised, multicentre, double-blind, placebo-controlled trial of etanercept in adults with refractory heel enthesitis in spondyloarthritis: the HEEL trial. Ann Rheum Dis 2010;69:1430-5.

44. Ory PA, Gladman DD, Mease PJ. Psoriatic arthritis and imaging. Ann Rheum Dis 2005;64 Suppl 2:ii55-7.

45. Fukuda T, Umezawa Y, Asahina A, Nakagawa H, Furuya K, Fukuda $\mathrm{K}$. Dual energy CT iodine map for delineating inflammation of inflammatory arthritis. Eur Radiol 2017;27:5034-40.

46. Fukuda T, Umezawa Y, Tojo S, Yonenaga T, Asahina A, Nakagawa

Personal non-commercial use only. The Journal of Rheumatology Copyright @ 2020 . All rights reserved. 
$\mathrm{H}$, et al. Initial experience of using dual-energy CT with an iodine overlay image for hand psoriatic arthritis: comparison study with contrast-enhanced MR imaging. Radiology 2017;284:134-42.

47. Taniguchi Y, Arii K, Kumon Y, Fukumoto M, Ohnishi T, Horino T, et al. Positron emission tomography/computed tomography: a clinical tool for evaluation of enthesitis in patients with spondyloarthritides. Rheumatology 2010;49:348-54.

48. Carron P, Lambert B, Van Praet L, De Vos F, Varkas G, Jans L, et al. Scintigraphic detection of TNF-driven inflammation by radiolabelled certolizumab pegol in patients with rheumatoid arthritis and spondyloarthritis. RMD Open 2016;2:e000265.
49. ClinicalTrials.gov. Study of efficacy and safety of secukinumab in psoriatic arthritis and axial spondyloarthritis patients with active enthesitis including one Achilles tendon site (ACHILLES). [Internet. Accessed March 25, 2020.] Available from: clinicaltrials. gov/ct2/show/record/NCT02771210

50. ClinicalTrials.gov. Study of power Doppler ultrasound (PDUS) to measure response of secukinumab treatment in patients with active psoriatic arthritis (PsA) (PDUS). [Internet. Accessed March 25, 2020.] Available from: clinicaltrials.gov/ct2/show/NCT02662985. 